\title{
Age differences in the outcome of long-delay taste-aversion conditioning in rats
}

\author{
JAMES R. MISANIN and DOUGLAS L. GREIDER \\ Susquehanna University, Selinsgrove, Pennsylvania \\ and \\ CHARLES F. HINDERLITER \\ University of Pittsburgh at Johnstown, Johnstown, Pennsylvania
}

\begin{abstract}
Weanling, young-adult, and aged rats were subjected to taste-aversion conditioning with a relatively weak US ( $1 \%$ body weight i.p. injection of $.15 \mathrm{M} \mathrm{LiCl})$ at one of four CS-US intervals $(0$, $0.75,1.5$, and $3.0 \mathrm{~h}$ ). Age differences occurred at all intervals, with aged rats showing superior conditioning. Increasing the CS-US interval was more disruptive the younger the rat. Although not unequivocal, the results suggest that the processes involved in associative memory during taste-aversion conditioning may involve different processes from those that mediate long-delay learning in more conventional learning tasks.
\end{abstract}

There is ample evidence that both reference memory (i.e., the long-term maintenance of acquired associations between events; e.g., Gold \& McGaugh, 1975) and working memory (i.e., the memory process that permits correct discriminative behavior on the basis of trace stimuli; Zornetzer, Thompson, \& Rogers, 1982) are impaired with aging in rats (Kubanis \& Zornetzer, 1981). In contrast, it is not clear whether the associative memory capability (i.e., the memory capability that is necessary for good performance when there is a long delay between two events to be associated) of aged rats is impaired. Although Doty (1966) found aged rats to be significantly inferior to young-adult rats on a delayed avoidance task, Ingram and Peacock (1980) reported little evidence of significant age differences in saccharin aversions conditioned in mature rats with short (15-min) and long (1- to 4-h) conditioned stimulus-unconditioned stimulus (CS-US) intervals.

Ingram and Peacock's (1980) failure to find age differences may have been due to their relatively intense US. The results of a recent study (Misanin, Blatt, \& Hinderliter, 1985) indicate that age differences in conditioned taste aversion may be obscured by a US of even moderate intensity. Furthermore, Hinderliter and Misanin (1988), using a weaker US $(.15 \mathrm{M} \mathrm{LiCl})$ than that used by Ingram and Peacock (.4M LiCl), found that both weanling and aged rats showed substantially less aversion to a novel flavor than did young adults when the illnessinducing US was delayed $1 \mathrm{~h}$ after access to the flavor CS. Hinderliter and Misanin, unlike Ingram and Peacock, however, did not systematically manipulate the CS-US interval. Thus, the purpose of the present study was to

Thie research was supported by Grant HD21161 from the National Institute of Child Health and Human Development to the first author. Reprint requests are to be sent to James R. Misanin, Department of Psychology, Susquehanna University, Selinsgrove, PA 17870. use a weaker US intensity than that used by Ingram and Peacock (1980) and systematically manipulate the CS-US interval in the long-delay taste-aversion conditioning of weanling, young-adult, and aged rats to determine at what CS-US intervals age differences emerge.

\section{METHOD}

\section{Subjects}

The rats used were 40 female Wistar albino rats from each of three age groups: weanling (21-24 days), young adult (76-96 days), and aged (680-825 days). All animals were born in the university animal colony. Animals of like age and treatment were housed 4 to a cage. They had access to food at all times, except during drinking sessions that were $1 \mathrm{~h}$ or less.

\section{Apparatus}

Cylinders (graduated to $1 \mathrm{ml}$ ) with rubber stoppers and stainless steel sipper tubes were used during all drinking sessions. The drinking sessions took place in standard suspended galvanized rodent cages that had spring-grip clamps attached to the center and the sides of the front of the cage to hold the cylinders. Except during testing, the cylinders were attached to the center of the front of the cage.

\section{Procedure}

Following an initial $23 \mathrm{~h}$ of water deprivation, all animals were given three daily 1-h adaptation sessions in the drinking cages, during which time they had access to room-temperature tap water. Seventeen hours following the last adaptation session, 32 animals (experimentals) at each age level were given a $1 \%$ body weight i.p. injection of $.9 \% \mathrm{NaCl}$ (physiological saline). The remaining 8 animals (explicitly unpaired controls) at each age level received a $1 \%$ body weight i.p. injection of $.15 \mathrm{M}$ lithium chloride $(\mathrm{LiCl})$. Six hours later all animals were given 10-min access to a $1 \%$ ( $w / v$ in tap water) saccharin solution. The 32 experimental subjects at each age level were randomly divided into four groups of 8 subjects. Each of these subjects was given a $1 \%$ body weight i.p. injection of $.15 \mathrm{M} \mathrm{LiCl}$ at different temporal intervals following the 10 min access to saccharin. These CS-US intervals were $0,0.75,1.5$, and $3.0 \mathrm{~h}$. The 8 control animals at each age level received a $1 \%$ body weight i.p. injection of physiological saline immediately $(0 \mathrm{~h})$ after access to the saccharin solution. Twenty-four hours after access to the saccharin, all animals were given a 24 -h two-bottle test (saccharin and water). 
During this test the cylinders were attached $35 \mathrm{~mm}$ in from each side of the front of the cage. The side on which saccharin was presented was counterbalanced for each group. The amount of each liquid consumed was recorded at access times of $1,6,18$, and $24 \mathrm{~h}$.

\section{RESULTS}

The amount of water and saccharin solution consumed at each of the four access times was computed for each rat and converted to a preference score: percent preference for saccharin $=100 \times$ saccharin intake/(saccharin + water intake). The preference scores were averaged for groups; group results are shown in Figure 1. With the significance level set at .05 , planned comparisons were made between the average preference scores of the experimental and control groups at each age level. The weanlings differed at the 0 -h CS-US interval $[F(1,105)$ $=13.00]$, but not at the other CS-US intervals $[F \mathrm{~s}(1,105)$ $<1.6]$. The young-adult experimentals differed from the controls at the $0,0.75$, and $1.5 \mathrm{~h}$ intervals $\left[F_{\mathrm{S}}(1,105)>\right.$ 4.59], but not at the 3.0-h CS-US interval. The aged experimental rats differed from controls at all CS-US intervals $\left[F_{\mathrm{s}}(1,105)>6.48\right]$. Comparisons were also made between ages at each CS-US interval. The weanlings showed a significantly higher preference for saccharin than the aged animals at all intervals $\left[F_{\mathrm{s}}(1,105)>6.65\right]$, but differed significantly from the young adults only at the 0.75 -h interval $[F(1,105)=9.09]$. The young adults did not differ from the aged rats at the $0,0.75$, and 1.5 -h intervals, but showed a significantly greater preference for saccharin than the aged animals at the 3-h interval $[F(1,105)=4.89]$.

\section{DISCUSSION}

When the $\mathrm{LiCl}$ injection was delayed for $3 \mathrm{~h}$ after the saccharin was presented, only the aged group showed any sign of conditioning. When the CS-US interval was $0.75 \mathrm{~h}$ or $1.5 \mathrm{~h}$, only the young-adult and aged rats showed signs of conditioning. All age groups showed signs of con- ditioning at the 0-h CS-US interval, but conditioning of the weanlings differed significantly from that of the aged animals at this interval. Thus, age differences in long-delay taste-aversion learning between weanlings and mature animals begin to emerge with CS-US intervals less than $1 \mathrm{~min}$. Age differences in the long-delay taste-aversion learning of the two groups of more mature rats, however, were not evident with CS-US intervals of $1.5 \mathrm{~h}$ or less, but were evident at the 3-h interval. Although results of previous studies suggest that age differences in the formation of taste-illness associations are related to the length of the CS-US interval (Baker, Baker, \& Kesner, 1977), rather than to age differences in the efficacy of $\mathrm{LiCl}$, these studies did not employ aged rats. The present study thus extends the conclusions of Baker et al. by showing that age differences in long-delay taste aversion between young-adult and aged rats is also not due to age differences in the efficacy of $\mathrm{LiCl}$. At the 1.5-h CS-US interval, neither the young-adult nor the aged rats suppressed drinking completely, and the conditioned aversion of these two age groups did not differ significantly, suggesting that the difference observed at the 3-h CS-US interval was not due to differential $\mathrm{LiCl}$ effects as a result of aging.

In one sense, these findings are not surprising. Results of several studies have shown that it is more difficult to condition an aversion to taste in weanling rats than in adults and that conditioned taste aversion fails to occur in young rats with long CS-US intervals (Baker et al., 1977; Gregg, Kittrell, Domjan, \& Amsel, 1978; Martin \& Timmins, 1980). Also, a recent study has shown that the ease with which an association is made between taste and an immediate illness is directly related to age in rats whose ages range from weanling to old age (Misanin et al., 1985). In another sense, the present results are surprising since previous work from our laboratory (Hinderliter \& Misanin, 1988) suggested that aged rats would be more likely to show poorer long-delay learning than young adults. There were, however, procedural differences between the two studies, as well as differences in the ages of the mature rats and in the way of assessing aversion; these may have contributed to the difference in the outcomes of the two studies.

The present findings are surprising in yet another sense, since they suggest that not only is long-delay taste-aversion learning not poorer in aged rats than in young adults, as is more conventional long-delay learning (e.g., Doty, 1966), but may actually be superior. If this is true, then the present results could indicate that associative memory in tasteaversion learning involves a different system from the one that mediates long-delay learning in more conventional learning settings. However, before such a conclusion can be drawn, it must be demonstrated that the observed difference in mature rats at the 3-h CS-US interval is due to age differences in the ability to maintain or reactivate the CS trace during the CS-US interval, and not to differences in US intensity as a result of different body weights and percent body weight injections

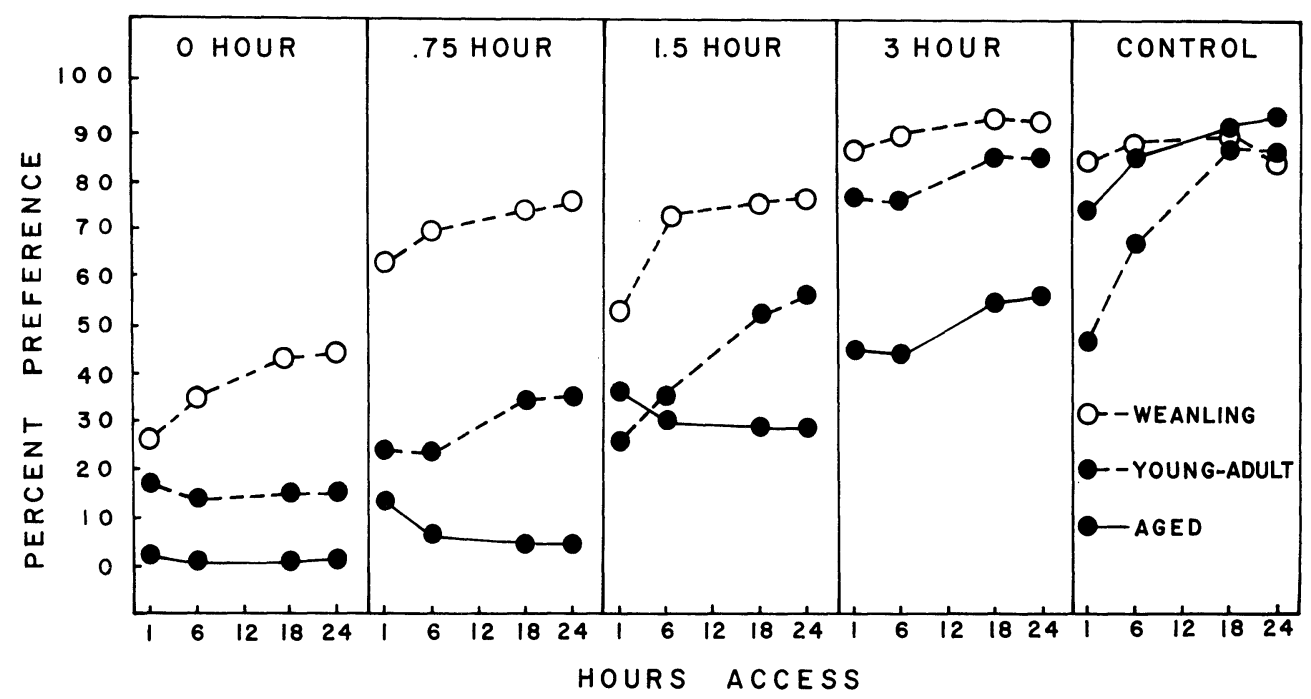

Figure 1. Percent preference for saccharin as a function of age (weanling, young-adult, aged), experimental CS-US intervals $(0, .75,1.5,3 \mathrm{~h})$ and control treatment, and hours access during testing $(1,6,18$, and 24$)$. 
of $\mathrm{LiCl}$, to age differences in context conditioning, or to age differences in the ability to learn safety during the CS-US interval.

\section{REFERENCES}

Baker, L. J., Baker, T. B., \& Kesner, R. P. (1977). Taste aversion learning in young and adult rats. Journal of Comparative \& Physiological Psychology, 91, 1168-1178.

DoTy, B. A. (1966). Age differences in avoidance conditioning as a function of distribution of trials and task difficulty. Journal of Genetic Psychology, 109, 249-254.

Gold, P. E., \& McGaugh, J. L. (1975). Changes in learning and memory during aging. In J. M. Ordy \& K. R. Brizee (Eds.), Advances in behavioral biology and neurobiology of aging (pp. 145-158). New York: Plenum Press.

GregG, B., Kittrell, E. M. W., Domjan, M., \& Amsel, A. (1978). Ingestional aversion learning in preweanling rats. Journal of Comparative \& Physiological Psychology, 92, 785-795.

Hinderliter, C. F., \& Misanin, J. R. (1988). Weanling and senes- cent rats process simultaneously presented odor and taste stimuli differently than young adults. Behavioral \& Neural Biology, 49, 112-117.

Ingram, D. K., \& Peacock, L. J. (1980). Conditioned taste aversion as a function of age in mature rats. Experimental Aging Research, 6, 113-123.

Kubanis, P., \& Zornetzer, S. F. (1981). Age-related behavioral and neurobiological changes: A review with emphasis on memory. Behavioral \& Neural Biology, 31, 115-172.

Martin, G. N.., \& Timmins, W. K. (1980). Taste-sickness associations in young rats over varying delays, stimulus, and test conditions. Animal Learning \& Behavior, 8, 529-533.

Misanin, J. R., Blatt, L. A., \& Hinderliter, C. F. (1985). Age dependency in neophobia: Its influence on taste-aversion learning and the flavor-preexposure effect in rats. Animal Learning \& Behavior, 13, 69-76.

ZoRnetZer, S. F., Thompson, R., \& Rogers, J. (1982). Rapid forgetting in aged rats. Behavioral \& Neural Biology, 36, 49-60.

(Manuscript received for publication September 23, 1987.) 